\title{
Inhalt
}

\section{Der Dichter}

Die Stimme der Muse (2008) - 3

Homeros (1998) 13

Homerische Frage (2000) -27

Zu Homers Person (2011) 41

\section{Die Vorgeschichte des Werkes}

Between Troy and Homer. The So-Called Dark Ages in Greece (1994) — 89

Die griechische Renaissance des 8. Jahrhunderts v. Chr.

Ein Überblick (2008) - 105

Der Beginn von Schriftlichkeit und Literatur (2008) - 117

Zwischen Mündlichkeit und Schriftlichkeit. Das Beispiel Homer (2003) — 135

Frühgriechische Epik und Lyrik in Ionien (2007) - 149

Epos II: Klassische Antike (1998) - 177

\section{Die Ilias}

Die Ilias: Inhalt und Aufbau (2008) - 191

Zur modernen Erzählforschung in der Homer-Interpretation (2005) — 237

Homer und die Ilias: Streit um Adelsideale (2001) — 251

Achilleus (unpubl.) -261

Achilleus. Wandlungen eines europäischen Heldenbildes (1995) - 267

A Battlefield of the Emotions: Homer's Helen (2007) - 347 
XVIII Inhalt

\section{Der Schauplatz: Troia}

Homers Ilias und die Folgen. Wie der Mythos Troia entstand (1991) — 361

Ex oriente lux (2006) -369

Joachim Latacz und Frank Starke

Wilusa und die Großen Vier - Troia in der politischen Landschaft der Späten Bronzezeit (2006) - 375

Troia und Homer. Neue Erkenntnisse und neue Perspektiven (1997) — 401

Der große Nachbar im Westen: Die Griechen - Was wußten sie von Troia?

(2001) -437

Troia - Wilios - Wilusa. Drei Namen für ein Territorium (22002) -443

Strukturiertes Gedächtnis. Zur Überlieferung der Troia-Geschichte durch die 'Dunklen Jahrhunderte' (2011) — 469

Poeten wissen, was man mit dem Material alles anstellen kann (2008) — 513 Troia lag nicht in Kilikien. Ein G/Geschichte-Gespräch mit Prof. Joachim Latacz (2008) -521

\section{Die Rezeption}

Alle kennen Homer (2008) $-\mathbf{5 2 9}$

Homer-Darstellungen in der antiken Literatur (2008) - 539

Homer-Kommentierung in Antike und Neuzeit. Von den Rhapsoden zum Basler Kommentar (2000/2013) — 557

Homer übersetzen. Zu Raoul Schrotts neuer Ilias-Fassung (2006) — 589

Warum Homer? (2008) -613

Das Troia Homers, das Troia der Geschichte und das Troia

Wolfgang Petersens (2007) - 621

Homer und Europa. Höhepunkte Homerischen Einflusses auf Europas

Kulturentwicklung (2012) - 641

Anhang:

Schriftenverzeichnis Joachim Latacz 1965-2014 - 669 